\title{
Visualizing regional clusters of Sardinia's EU supported agriculture: A Spatial Fuzzy Partitioning Around Medoids
}

\author{
Pierpaolo D'Urso ${ }^{\mathrm{a}}$, Germana Manca ${ }^{\mathrm{b}, *}$, Nigel Waters ${ }^{\mathrm{c}}$, Stefania Girone ${ }^{\mathrm{d}}$ \\ ${ }^{a}$ Dipartimento di Scienze Sociali ed Economiche, Sapienza - Università di Roma, P.za Aldo Moro 5, Rome 00185, Italy \\ ${ }^{\mathrm{b}}$ Department of Environmental Science and Policy, George Mason University, 4400 University Dr MS 5F2, Fairfax, VA 22030, United States \\ ${ }^{\mathrm{c}}$ University of Calgary, Calgary, $A B$, Canada \\ ${ }^{\mathrm{d}}$ Dipartimento di Scienze agro-ambientali e territoriali (DISAAT), University of Bari, Piazza Umberto I, Bari 70121, Italy
}

\section{A R T I C L E I N F O}

\section{Keywords:}

Agri-environmental measures

Common Agriculture Policy (CAP)

Spatial Fuzzy Partitioning Around Medoids

(SFPAM)

Geographical information science (GIS)

Regional development

\begin{abstract}
A B S T R A C T
The recurrent question about the effectiveness of agri-environmental measure (AEM) in Sardinia (Italy) is whether European Union (EU) funds allocate resources to where they are most needed. To answer this question, a spatial approach is suggested, namely an approach that considers geography as a factor in measuring the success of such policy. A geographical approach can be used to pinpoint "hotspots" in order to determine an appropriate distribution of funds. To implement such an approach to the distribution of EU funding, a Spatial Fuzzy Partitioning Around Medoids (SFPAM) analysis is advocated. The contribution of this research is that it combines a temporal dimension within an explicitly spatial approach. It achieves this by using a dataset that includes both geographical and economic factors such as farm sizes, their management, the number of organic farms involved, the agriculture area invested by the AEM and the size of the workforce involved. Its strategy is the identification of medoids which are represented by a specific municipality. This allows the identification of aggregated neighborhoods for the visualization of AEM outcomes based on a fuzzy partitioning method. The results provide useful policy implications to determine where and when financial efforts should be renewed, where to negotiate sustainable development strategies, and how to expand spatially the benefits of financial funding to other agricultural measures, such as technological innovations in agriculture, reforestation programs, marketing strategies, climate change mitigation, and rural development.
\end{abstract}

\section{Introduction background and motivation}

In Sardinia, the European Union's (EU) Common Agriculture Policy (CAP) redesigns agricultural challenges through its 2014-2020 framework and uses its operating arm to distribute funds according to the CAP. EU member states are permitted to determine a range of different measures and to settle payments, based on regional needs and costs. Consequently, funds, from both national and EU contributions that total approximately a billion euros, are allocated in the Sardinian Region to finance several agricultural measures, including improving agricultural competitiveness, the preservation of natural resources, mitigation of the effects of climatic change, and strengthening the economic and social structure of rural communities over the duration of the program. Although the measures sound challenging for farmers, especially in response to climate change mitigation, the latest technological requirements, and awareness of the farmer's role in the protection of the environment, they are well known and established thanks to the close connection with the previous CAP framework program (2007-2013). Nevertheless, how to achieve the goals of economic growth and income equity in agriculture under changing environmental conditions is certainly a challenge. The agri-environmental policy (Yang et al., 2014) is selected in this paper, because it includes the fundamental concept of 'good farming', which emphasizes its importance with respect to the concerns of rural sociology (Riley, 2016). Essentially the agri-environmental schemes represent an effective method for delivering public funds to farmers that will reduce the negative environmental aspects of agricultural production. The farmer embodies the guardian of the environment, especially in areas of intensive agriculture that are characteristic of the Italian landscape.

Nevertheless, a debate remains regarding the real outcome of these new measures. Burton and Schwarz (2013) stated that a potential issue is that "one of the key problems with the action-oriented schemes is

\footnotetext{
* Corresponding author.

E-mail addresses: pierpaolo.durso@uniroma1.it (P. D’Urso), germana.manca@gmail.com (G. Manca), nwaters@ucalgary.ca (N. Waters), stefaniagirone@hotmail.com (S. Girone).
} 
their failure to promote long-term behavioral change", although they list several examples of positive change, induced by voluntary measures. An important outcome of these measures is determined by their multifunctionality, which is emphasized by the length of the 2014-2020 funding period. Galler et al. (2015) quantified "effectiveness of the measures, as well as spatial cost efficiency with respect to four key landscape functions: erosion prevention, water quality conservation, climate change mitigation and safeguarding biodiversity." Moreover, these authors describe how self-management enhanced the realization of efficient agricultural solutions.

The spatial variable has been used extensively in several studies across Europe and it is considered essential in evaluating the effectiveness of any given measure. Nevertheless, Bateman et al. (2013) state that the actual payment structure is 'spatially insensitive'. Other authors affirm the importance of spatial analysis used to understand the development of AEM. Among them, Yang et al. (2014), in Scotland, applied spatial econometrics to determine the importance of "particular explanatory variables such as farming characteristics, land capability, designated sites, and accessibility and population." The outcomes of their analysis demonstrated how spatial dependency of the variables supports the application of "spatially-explicit models." In Italy, Diti et al. (2015) applied an integrated spatial analysis, through a geographical information system (GIS), to identify rules that would permit the implementation of political actions to sustain rural management. Their integrated methods allow the development of scenarios that include a geographical framework. To strengthen the importance of spatial influence, Lobianco and Esposti (2010) developed RegMas, a spatial approach based on an Agent Based Model. The software assesses the impact of CAP and predicts the farmers' behavior based on geographical locations and changes to be made in policy. Additionally, Palmisano et al. (2016a) used a Multicriteria Decision Spatial Decision Support System that integrated a GIS with Multicriteria Decision methods to provide a spatial tool that would show policy makers how they could both improve environmentally sustainable implementations of the CAP and find a suitable compromise with alternatives that were promoted by the various stakeholders. Again, Palmisano et al. (2016b) promoted a spatial approach with multicriteria decision analysis, providing a common decision making framework that would also be useful for the Local Action Groups involved in the Rural Sustainable Development inside the CAP. Furthermore, Matthews et al. (2013) designed a spatial analytical framework, involving data from biophysical and socio-economic domains to evaluate the outcome of the business incomes of farmers in Scotland, through a single payment of the CAP.

To contextualize the geographic pattern and understand the trend of the AEM in Sardinia, Manca et al. (2014) showed the importance of applying a geographically weighted regression analysis to understand, at a regional scale, the key indicators capable of achieving a successful and balanced approach to the AEM. Considering that, the geographical approach is important with datasets that have spatial attributes, these features can be managed in a GIS, and several methods are available to assess jointly the outcome of the regional AEM by observing the spatial pattern of the distribution of its effects. To make sense of the spatial extension dataset, an integrated approach is suggested. For these reasons, in many situations, clustering methods are the key to untangle the complexity of reality and for determining the behavior and role of important explanatory variables. Among these clustering methods, fuzzy modeling is an alternative analysis that copes with complex and challenging 'tractable' structures (Tsekouras, 2007). Tsekouras (2005) supports the method of Fuzzy Clustering as a key to dealing with datasets that have undefined boundaries. Nevertheless, the traditional fuzzy c-means approach (Tsekouras, 2005) does not consider a spatial frame, which is a suitable instrument for implementing the present analysis and determining, inside the temporal spatial dimension, the magnitude of the AEM's impact.

For a detailed review of fuzzy clustering see, e.g., D'Urso (2015). Franco and Senni (2003) used a fuzzy logic application to extract clusters of rural growth in Italian regions. Qiuzhen et al. (2012) in Finland used a fuzzy synthetic evaluation method that "offers an alternative way to evaluate the provision of public goods from agriculture", reinforcing the idea that fuzzy analysis represents a tool to assess the AEM measure, and whether it is influenced by its political incidence. A spatial fuzzy clustering approach has been used by Manca (2015) to evaluate the regional development of the AEM measure in Sardinia (Italy); the results show the spatial contiguity of the AEM, revealing the spatial pattern of the clustered municipalities. Essentially the fuzzy approach is versatility in understanding environmental indicators and translating them into a gradual perception, strengthening the concept of an agriculture sector that is in a transition period. For this reason, the present research used a Spatial Fuzzy Partitioning Around Medoids (SFPAM) method. This technique is useful for classifying geographical areas and was suggested by Pham (2001). The proposed clustering method incorporates the advantages connected with the fuzzy approach, the PAM procedure and the inclusion of spatial information. In more explicit detail the advantages of these three methods are:

- The fuzzy approach: the concept of partial membership underlying the fuzzy approach appears more appealing and flexible than that of traditional clustering methods (McBratney and Moore, 1985; Wedel and Kamakura, 1998). Furthermore, fuzzy clustering has been shown to be computationally more efficient because dramatic changes in the value of cluster membership are less likely to occur during the estimation procedures (McBratney and Moore, 1985) and clusters are less affected by local optima problems (Heiser and Groenen, 1997). In addition, the membership for any given set of observations indicates whether there is a second-best cluster that is almost as good as the best cluster. This is a result which traditional clustering models usually cannot uncover (Everitt et al., 2001).

- PAM procedure: by adopting the PAM approach each cluster is represented by an observed object, i.e., the medoid, and not by a fictitious or calculated object (the centroid), as in the fuzzy c-means clustering method. This is an appealing and useful result in the present study and is important for the interpretation of the resulting clusters. Furthermore, fuzzy c-medoids clustering based on the PAM approach represents improved robustness when compared with traditional fuzzy c-means clustering.

- Spatial information: by considering the spatial term in the clustering procedure, the fuzzy clustering method can deal appropriately with the distinguishing characteristics of spatial data, that is, spatial dependence and spatial heterogeneity.

The remaining sections of this paper are organized as follows: in Section 2, the empirical information (dataset) of the study is discussed; in Section 3, the suggested methodological approach for clustering geographical areas, i.e., municipalities, is explained. The results and discussion are described in Section 4. The conclusions are given in Section 5 .

\section{Dataset}

The datasets were obtained from the 2010 agricultural census collected by the Italian National Institute of Statistic (ISTAT), which is updated every ten years, and released on 2011. Data of the same years for the AEM and agricultural variables were obtained by the Sistema Informativo Agricolo Nazionale (SIAN). Eight variables have been chosen among the two datasets; five are based on a previous selection (Manca et al., 2014), where they were subjected to the geographically weighted regression analysis, while the rest have been recently added, thanks to the newly released database and they are related to the management form, inherent to the extension of the measure. The eight variables represent the basis of the analysis and make the results consistent with the original dataset. These variable indicators, listed below, 


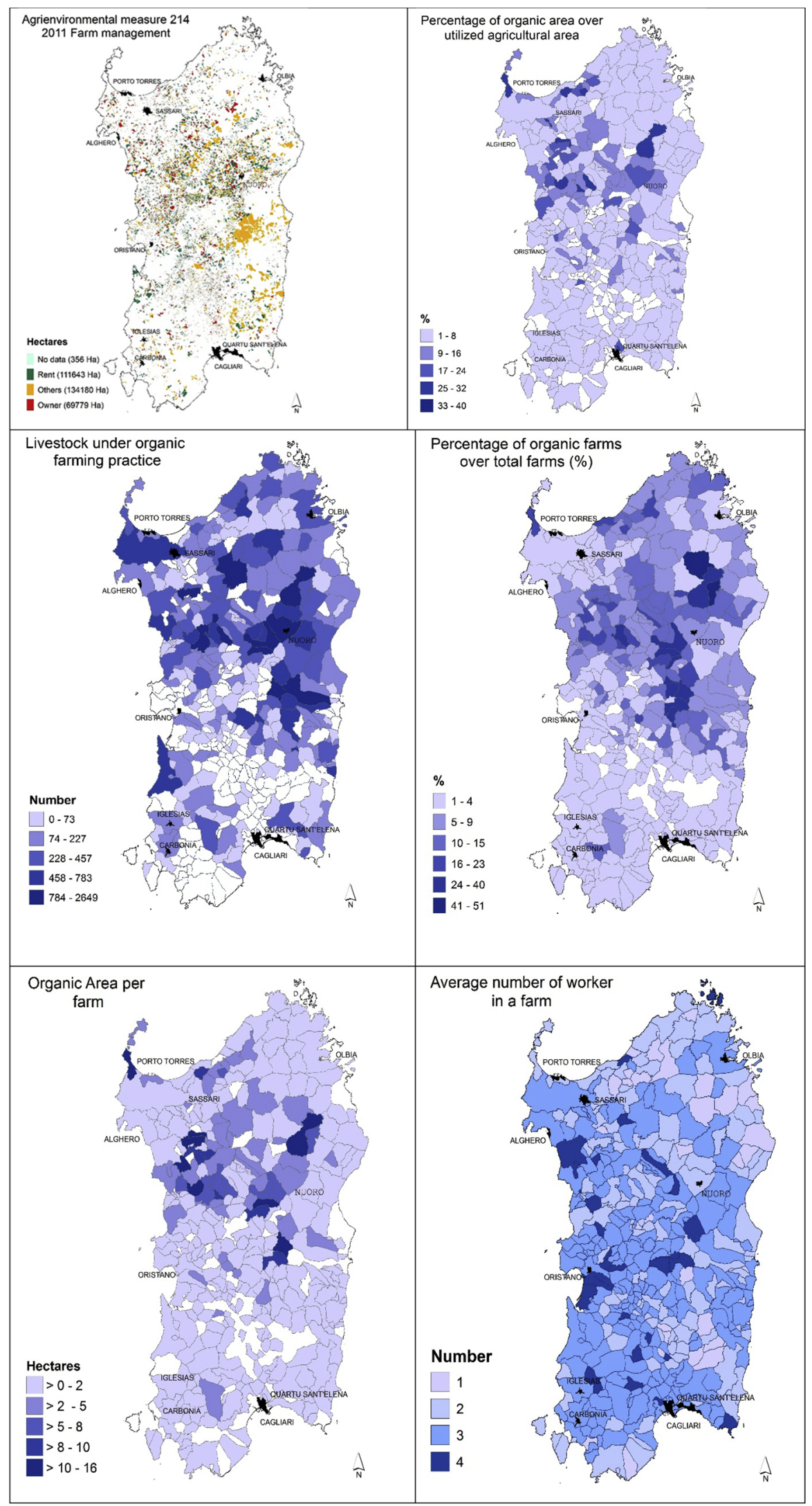

Fig. 1. Spatial extension of the criteria used in the analysis. 
cover 369 municipalities, affected by the measure.

1. Hectares of the agri-environmental measure area under rent management

2. Hectares of the agri-environmental measure area under owner management

3. Hectares of the agri-environmental measure area under other forms management

4. Percentage of organic area (OA) over the utilized agricultural area (UAA) (\%)

5. Livestock unit under organic farming practice (C.G.C.) (C.G.C is a measure of the average livestock number and it is calculated using the following equation: 1 calf $(500 \mathrm{~kg})=1$ buffalo $=1$ horse $=1.3$ donkeys $=5$ pigs $=10$ sheep $=10$ goats $=250$ rabbits $=250$ chickens $=100$ turkeys)

6. Percentage of organic farms over total farms (\%)

7. Organic area per farm (Are, $100 \mathrm{~m}^{2}$ )

8. Average number of workers on a farm

The spatial distribution of the variables has been shown in Fig. 1. Data come from the real estate registry of 2011, jointly connected with the cadastral data of the agri-environmental measure dataset. The other criteria are related to the municipalities as well, without the accuracy of the cadastral dataset. The common geographical key is the municipality.

To explain the meaning of the eight variables an empirical approach is used to clarify the complexity of the agricultural sector of the Region. Thus the indicators related to the management forms of the land parcels involved in the measure represent a major part of the AEM fields. Essentially, rent and other forms of management allow a dynamic form of management compared to traditionally owned land. For instance, the "other management" area, identified in the first figure and located in the central eastern region of the map, corresponds to the high values shown for organic farming and for livestock under organic farming practice. Although the geographical boundaries of this area are not related to the municipalities, the focus of this analysis is nevertheless informed by the municipal indicators, based on the census data. Thus, clustered municipalities, included in the geographical boundaries of the other management extension area, show highest values for farmers enrolled in advanced courses for best agriculture practices (Manca, 2015). Essentially the farmers of this cluster learned when to apply for government funding and how to achieve the aims of the AEM, taking advantage of the acquired knowledge.

More importantly, the pastoral activities, quantified by the C.G.C. number, and their products represent a good example of dairy production chain, managed by entrepreneurs and traditional economic occupations (Idda et al., 2010). In Sardinia agro-pastoral activity has been the objective of anthropological and economic study by VargasCetina (2000) and it has been acknowledged to be important in regional productivity, especially for the export of pecorino cheese worldwide. In addition, Ligda et al. (2011) underlined how tradition and innovation in Mediterranean pastoralism have found a common language in the application of agri-environmental measures, allowing the protection of the environment and biodiversity and permitting a response to consumer demands concerning the safety of the products.

\section{Method}

In this paper, a clustering approach is adopted. In the literature, with respect to the objects to be classified, two spatial clustering approaches have been proposed: spatial clustering for geographical areas and spatial clustering for pixels.

The spatial clustering for geographical areas, is defined by means of administrative boundaries (Coppi et al., 2010), and aims at determining groups of geographical areas such that the within group dispersion of the variable set is minimized along with the additional assumption that the configuration of the obtained clusters should satisfy spatial constraints. Generally, it is required that the clusters are formed by spatially contiguous areas. Therefore, a geographical unit can be assigned to a specific group only when it is contiguous to at least one area belonging to the group that is already defined. It also follows that two groups can be merged into one group if at least one spatial unit belonging to one group is contiguous to at least one spatial unit belonging to the other group. A different approach to the problem consists of relaxing the contiguity constraints if such constraints are shown to be too restrictive for practical purposes (Murtagh, 1985). However, the main idea underlying both approaches can be found in the empirical evidence that spatial data are often characterized by positive spatial autocorrelation: neighboring sites tend to have similar features (Waters, 2017). If such spatial autocorrelation affects the observed data, this should be explicitly dealt with in the clustering model, instead of arbitrarily ignoring it, so that the resulting clusters may incorporate it (Gordon, 1996).

Following the spatial clustering for pixels, traditional partitioning methods aim at assigning the pixels in an image to different clusters by considering their aspatial characteristics. Classic clustering methods do not consider the information connected to the spatial distribution of the pixels. To solve this problem, spatially aware clustering procedures have been adapted to include spatial information (Coppi et al., 2010). Examples of clustering techniques belonging to this class have been described in Pham (2001) and Xia et al. (2007). A Spatial Fuzzy Partitioning Around Medoids (SFPAM) method that is a C-medoids version for classifying geographical areas (in the present case, municipalities) based on the Fuzzy C-Means clustering method with the spatial term suggested by Pham (2001) was used in the present study.

This method can be described as follows: let $\mathbf{X} \equiv\left\{\mathbf{x}_{i}=\left(x_{i 1} \ldots x_{i j} \ldots x_{i J}\right)^{\prime}: i=1, \ldots, I\right\}$ be the data matrix concerning a set of $I$ geographic areas on which the values taken by $J$ variables are recorded. Then, the Spatial Fuzzy Partitioning Around Medoids (SFPAM) method can be formalized as follows:

$\min : \sum_{i=1}^{I} \sum_{c=1}^{C} u_{i c}^{m}\left\|\mathbf{x}_{i}-\tilde{\mathbf{x}}_{c}\right\|^{2}+\frac{\beta}{2} \sum_{i=1}^{I} \sum_{c=1}^{C} u_{i c}^{m} \sum_{i^{\prime}=1}^{I} \sum_{c^{\prime} \in C_{c}} p_{i i^{\prime}} u_{i^{\prime} c^{\prime}}^{m}$ $\sum_{c=1}^{C} u_{i c}=1 ; u_{i c} \geq 0$

where: $u_{i c}$ denotes the membership degree of the $i$ th geographical area $(i=1, \ldots, I)$ in the $c$ th cluster $(c=1, \ldots, C)$ (the optimal number of clusters is obtained by means of suitable cluster validity criteria; D'Urso, 2015); $\left\|\mathbf{x}_{i}-\tilde{\mathbf{x}}_{c}\right\|^{2}$ indicates the squared Euclidean distance between the ith geographical area and the $c$ th medoid geographical area $\tilde{\mathbf{x}}_{c} ; m>1$ controls the extent of membership sharing among fuzzy clusters (D'Urso, 2015); $C_{c}=\{1, \ldots, c-1, c+1, \ldots, C\} ; \beta \geq 0$ (multiplying $\beta$ by one half is useful for mathematical reasons when determining the optimal values of the membership degrees (Coppi et al., 2010)); $p_{i i^{\prime}}$ indicates the spatial information connected to each pair of $i$ th and $i^{\prime}$-th geographical areas; in particular: $p_{i i^{\prime}}= \begin{cases}1 & \text { if geographical areaiis contiguous to geographical areai', } \\ 0 & \text { otherwise. }\end{cases}$

A value between 1 and 1.5 for $m$ is recommended by Kamdar and Joshi (2000). For a discussion and a list of references on the choice of $m$ see D'Urso et al. (2015).

The objective function in Eq. (1) is constituted by two terms:

$\sum_{i=1}^{I} \sum_{c=1}^{C} u_{i c}^{m}\left\|\mathbf{x}_{i}-\tilde{\mathbf{x}}_{c}\right\|^{2}$ : this represents the objective function of the Fuzzy C-medoids Clustering method (or, alternatively, Fuzzy Partitioning Around Medoids method, i.e., the FPAM method).

$\frac{\beta}{2} \sum_{i=1}^{I} \sum_{c=1}^{C} u_{i c}^{m} \sum_{i^{\prime}=1}^{I} \sum_{c^{\prime} \in C_{c}} p_{i i^{\prime}} u_{i^{\prime} c^{\prime}}^{m}$ t this represents the spatial penalty term (often referred to as the spatial regularization term). The objective function is formed according to a twofold goal. First, it should act in such a way that the membership degree of an observation unit in each cluster is negatively correlated with the membership degrees of the neighboring observation units in the other clusters. Second, it should also consider the existing spatial autocorrelation of the dataset at hand.

Notice that the use of a spatial penalty term does not generally 
constrain the obtained clusters to be solely formed by neighboring spatial units. Instead it simply makes it more likely that clusters will be formed by neighboring spatial units. The spatial penalty term is based on the following assumption. When a geographical area $i$ belongs to cluster $c$ with a high membership degree, then Eq. (1) forces the neighboring geographical areas to have a high membership probability in cluster $c$. The parameter $\beta$ plays the role of increasing or decreasing the emphasis of the spatial penalty term in the minimization of Eq. (1). For choosing $\beta$ it is desirable that its value, which is chosen in advance, should be relatively high in the case of a concordance between the features of neighboring geographical areas and relatively low in the contrary case (Coppi et al., 2010). When $\beta=0$, the spatial aspects of the data do not affect the clustering and Eq. (1) it reduces to the FPAM method. Extremely high values of $\beta$ may lead to abnormal results of the clustering procedure in the sense that the spatial units are assigned to the clusters considering only the spatial constraints and ignoring all the aspatial variables. A procedure for choosing the optimal value of $\beta$ has been suggested by Coppi et al. (2010). Essentially $\beta$ has been empirically chosen. Although several values of $\beta$ have been evaluated, nevertheless the one selected provides a lexical understandable partition and moreover consistent and contextual with the regional development analysis.

By solving the constrained optimization problem (1) with the Lagrange multiplier method, the iterative solutions are given by Eq. (2) (Pham, 2001; Coppi et al., 2010):

$u_{i c}=\frac{\left[\left\|\mathbf{x}_{i}-\tilde{\mathbf{x}}_{c}\right\|^{2}+\beta \sum_{i^{\prime}=1}^{I} \sum_{c^{\prime} \in C_{c}} p_{i i^{\prime}} u_{i^{\prime} c^{\prime}}^{m}\right]^{-1 /(m-1)}}{\sum_{c^{\prime \prime}=1}^{C}\left[\left\|\mathbf{x}_{i}-\tilde{\mathbf{x}}_{c^{\prime \prime}}\right\|^{2}+\beta \sum_{i^{\prime}=1}^{I} \sum_{c^{\prime \prime} \in C_{c}} p_{i i^{\prime}} u_{i^{\prime} c^{\prime \prime}}^{m}\right]^{-1 /(m-1)} .}$

\section{Results and discussion}

Running the SFPAM method and setting the parameters as $\beta=3.3$ and $m=1.5$, the optimal partition is determined by six clusters. Table 1 shows the numerical values of the medoids.

The results seem to look odd in the map at first glance and not understandable until a graphic/geographic perspective allows us to discriminate among municipal differences. Weber Reuschel et al. (2014) pointed out the need for choosing a proper cartographic representation of the map, especially when it is based on clustered map features, without losing an overview of the entire region under investigation. They suggest using a cartogram procedure that maintains topological relationships while stretching high valued areas and shrinking the lower valued regions. For this reason, to visually understand the results of the clustering approach, a cartogram technique (Gastner and Newmann, 2004) has been applied (Fig. 2).

Six clusters are shown in Fig. 2, and the resulting clustered map is distorted using the previously described cartogram method. The thematic distortion of the municipalities reveals that some of them either with no data or low values are still shown, while an enlarged region is locally distorted to magnify the importance of higher values. Using this cartogram visualization, the clustered map is well depicted, allowing discrimination among clusters with small differences. The exaggeration or distortion in the cartogram is determined by the criteria used to calculate the PFAM value. Thus, the map visualization and justification have benefited from an empirical approach, which is based on the economic and social structure of the municipalities.

Remarkably, it is noted that eight municipalities do not count AEM hectares: these are Elmas, Sant'Anna Arresi, Ollastra Simaxis, Piscinas, the small islands La Maddalena and Carloforte. They belong to the cluster one, whereas Golfo Aranci, San Teodoro belong to cluster five, while the other municipalities recall for extensive urban expansion or touristic demands, while the last two are characterized by shrinking population and, even if the extension of agricultural area is proportionally high to the total extension, traditionally family management. A key lecture reading up for a low membership value is the altitude from sea level. Most of the municipalities settled in the mountain or high hills. Although the development is not based on intensive agriculture, it could be expected that these municipalities would have a push toward the organic production, which is not happening. Stagnation wraps the area and a further political action would be projected to determine a development, based on its own peculiarity.

The medoid of cluster one is the municipality of Fordongianus. Two hundred and thirty-three municipalities belong to this group. The shades of cluster colors are related to the increasing membership value, and the highest values of membership are geographically located along two diagonals virtual lines, representing the Campidano, an alluvial plain historically cultivated by old-style farmers, which is still dominated by traditional agriculture, and same pattern is shown along the other diagonal, moving from Cixerri through Trexenta. The data from this area show low percentages of organic extensions, low levels of cattle under organic conditions and low number of organic farms. Regarding the AEM, this cluster is mostly sustained by AEM rent management, with some notable excellence niches in organic production, although it is distinguished by a traditional agricultural pattern. The adjacent land surroundings the east cluster side show a gradual decrease of membership values.

In the future, the municipalities in this cluster will probably split off into a separate one.

Cluster two includes sixteen municipalities with Borore as the defined medoid. The cluster does not share the same geographical homogeneity as the previous one, considering that some municipalities are located along the coast while others are in the mountainous regions. Moreover, the demographic structure, based on the SMD index (Stato di Malessere Demografico: a social structure index, based on the percentage population fluctuations between 1951 and 2001 and between 2001 and 2011, elderly index, ratio between child and elderly, dependence index among young and elderly, and finally depopulation between 1951 and 2011), that measures demographic health, (Bottazzi and Puggioni, 2012), fluctuates between a state of demographic health and a serious level of declining population, revealing the structural heterogeneity of the cities in this cluster. The members of this cluster vary in their geographical-environmental features and in their SMD index and thus it is their similarity in their use of organic agriculture that binds them together as a distinct group. Although Dualchi, is a small municipality in this cluster and a neighbor of the medoid, Borore, the extension of land under organic practice is more than just traditional. In this group, renting and other forms of management represent the highest amount of land under the AEM. This is a mature cluster because of the balance between an extension of organic agriculture and the AEM form of management, but also unstable because of the environmentalgeographical and social diversity. This uncertain situation will probably result in newly developed clusters.

The group of municipalities belonging to cluster three is heterogeneous and in the middle of a transitional phase that is moving them away from agriculture toward the development of other sectors. For instance, Tertenia has had a lucrative summer tourist industry in the last ten years and, as the demand for such services has increased, the workforce has moved into the tourist sector. Similar comments could be made for the municipality of Castelsardo but here the geography differs because of the municipality's adjacency to Porto Torres. In the last few decades the municipality of Porto Torres suffered and still suffers from the economic failure of its industrial pole, and it has been unable to attract new activities and has had to develop a different regional role and identity. For this reason, Castelsardo has switched to the tourist industry, rather than developing satellite activities in support of the industrial pole formerly located at Porto Torres. Counter intuitively, Norbello is the medoid for this cluster. What do they share? Its economy is based on a flourishing organic farming industry located in a fertile plain. It has also developed a tourist sector, attracting many visitors due to its lengthy history. 
Table 1

The cluster partitioning.

\begin{tabular}{|c|c|c|c|c|c|c|c|}
\hline \multicolumn{8}{|c|}{ Cluster one } \\
\hline Municipality & $m$ & Municipality & $m$ & Municipality & $m$ & Municipality & $m$ \\
\hline NORAGUGUME & 0,21 & GESICO & 0,55 & SENORBI & 0,92 & MASAINAS & 0,99 \\
\hline TONARA & 0,22 & PALMAS ARBOREA & 0,59 & NEONELI & 0,93 & VALLERMOSA & 0,99 \\
\hline OSSI & 0,22 & NURAGUS & 0,60 & MILIS & 0,93 & OLLASTRA SIMAXIS & 0,99 \\
\hline TIANA & 0,24 & SODDI & 0,60 & ESCOLCA & 0,93 & GUASILA & 0,99 \\
\hline OVODDA & 0,24 & AUSTIS & 0,61 & VILLAURBANA & 0,94 & VILLASPECIOSA & 0,99 \\
\hline ESCALAPLANO & 0,24 & SOLARUSSA & 0,63 & BARRALI & 0,94 & IGLESIAS & 0,99 \\
\hline ANELA & 0,25 & CASTIADAS & 0,63 & VILLANOVAFRANCA & 0,94 & SESTU & 0,99 \\
\hline USINI & 0,25 & BELVI & 0,65 & ALBAGIARA & 0,94 & COLLINAS & 0,99 \\
\hline SADALI & 0,25 & ARDAULI & 0,66 & SIAMANNA & 0,94 & SINI & 0,99 \\
\hline MONTELEONE ROCCA DORIA & 0,26 & BONARCADO & 0,66 & S. NICOLO D'ARCIDANO & 0,94 & MORGONGIORI & 0,99 \\
\hline ULASSAI & 0,26 & LA MADDALENA & 0,66 & GENONI & 0,95 & LAS PLASSAS & 0,99 \\
\hline BURCEI & 0,27 & RUINAS & 0,67 & SANTA GIUSTA & 0,95 & PISCINAS & 0,99 \\
\hline URZULEI & 0,27 & SENEGHE & 0,68 & NURECI & 0,95 & MASULLAS & 0,99 \\
\hline MONTRESTA & 0,27 & PIMENTEL & 0,72 & FLUMINIMAGGIORE & 0,95 & SERRENTI & 0,99 \\
\hline VILLAPUTZU & 0,27 & BAULADU & 0,73 & USSARAMANNA & 0,95 & VILLAMASSARGIA & 0,99 \\
\hline MONSERRATO & 0,27 & SAN BASILIO & 0,74 & ELMAS & 0,95 & CABRAS & 0,99 \\
\hline PAULILATINO & 0,27 & GIBA & 0,76 & ALES & 0,96 & MARRUBIU & 0,99 \\
\hline VALLEDORIA & 0,28 & GUAMAGGIORE & 0,76 & SIMAXIS & 0,96 & VILLANOVAFORRU & 0,99 \\
\hline JERZU & 0,28 & TEULADA & 0,77 & VILLANOVA TRUSCHEDU & 0,96 & TUILI & 0,99 \\
\hline ASUNI & 0,28 & ZERFALIU & 0,77 & GENURI & 0,96 & RIOLA SARDO & 0,99 \\
\hline LANUSEI & 0,29 & SORGONO & 0,78 & PAU & 0,96 & SAN VERO MILIS & 0,99 \\
\hline LOCERI & 0,29 & DOLIANOVA & 0,78 & MANDAS & 0,96 & SIRIS & 0,99 \\
\hline GIRASOLE & 0,29 & MOGORELLA & 0,80 & SETTIMO S. PIETRO & 0,96 & SERDIANA & 0,99 \\
\hline USSASSAI & 0,29 & BORONEDDU & 0,80 & CAGLIARI & 0,97 & VILLASOR & 0,99 \\
\hline GAIRO & 0,29 & NURRI & 0,80 & TERRALBA & 0,97 & SANTADI & 0,99 \\
\hline LEI & 0,29 & TADASUNI & 0,80 & SEGARIU & 0,97 & TURRI & 0,99 \\
\hline SORRADILE & 0,30 & SANT'ANDREA FRIUS & 0,82 & URAS & 0,97 & QUARTU S.ELENA & 0,99 \\
\hline NURALLAO & 0,30 & PULA & 0,82 & SAMASSI & 0,97 & MONASTIR & 0,99 \\
\hline LACONI & 0,30 & GERGEI & 0,82 & USSANA & 0,97 & MUSEI & 0,99 \\
\hline GUSPINI & 0,30 & BUGGERRU & 0,82 & ULA TIRSO & 0,97 & SIAPICCIA & 0,99 \\
\hline TORTOLI & 0,32 & ORROLI & 0,82 & NARCAO & 0,97 & PORTOSCUSO & 0,99 \\
\hline GAVOI & 0,32 & S. GAVINO MONREALE & 0,83 & MARACALAGONIS & 0,97 & ORTUERI & 0,99 \\
\hline CARDEDU & 0,33 & VILLASIMIUS & 0,83 & BUSACHI & 0,97 & NURACHI & 0,99 \\
\hline BALLAO & 0,34 & ARBOREA & 0,84 & SIURGUS DONIGALA & 0,97 & TRATALIAS & 0,99 \\
\hline TETI & 0,34 & PABILLONIS & 0,84 & SETZU & 0,98 & CURCURIS & 0,99 \\
\hline MODOLO & 0,35 & GONNOSFANADIGA & 0,85 & SOLEMINIS & 0,98 & LUNAMATRONA & 0,99 \\
\hline VILLANOVA TULO & 0,36 & QUARTUCCIU & 0,85 & TRAMATZA & 0,98 & SARDARA & 0,99 \\
\hline ISILI & 0,37 & SUELLI & 0,86 & GONNESA & 0,98 & POMPU & 0,99 \\
\hline CARLOFORTE & 0,37 & ALLAI & 0,86 & ASSOLO & 0,98 & BARUMINI & 0,99 \\
\hline MURAVERA & 0,38 & USELLUS & 0,87 & ORISTANO & 0,98 & DECIMOMANNU & 0,99 \\
\hline BURGOS & 0,38 & SILIUS & 0,87 & ORTACESUS & 0,98 & S. GIOVANNI SUERGIU & 0,99 \\
\hline ESPORLATU & 0,39 & CALASETTA & 0,87 & MOGORO & 0,98 & SERRAMANNA & 0,99 \\
\hline LODINE & 0,41 & GONI & 0,87 & ZEDDIANI & 0,98 & PAULI ARBAREI & 0,99 \\
\hline NUGHEDU S. VITTORIA & 0,42 & VILLA S.ANTONIO & 0,88 & SANT'ANNA ARRESI & 0,98 & BARATILI S. PIETRO & 0,99 \\
\hline SELARGIUS & 0,42 & NARBOLIA & 0,88 & NURAMINIS & 0,98 & BARESSA & 0,99 \\
\hline BARISARDO & 0,42 & VILLA SAN PIETRO & 0,88 & CAPOTERRA & 0,99 & BARADILI & 0,99 \\
\hline MEANA SARDO & 0,42 & VILLA VERDE & 0,88 & CARBONIA & 0,99 & GONNOSNO & 0,99 \\
\hline PERDASDEFOGU & 0,43 & SAMUGHEO & 0,89 & UTA & 0,99 & VILLAPERUCCIO & 0,99 \\
\hline SAN NICOLO GERREI & 0,43 & SILIQUA & 0,89 & VILLACIDRO & 0,99 & SAN SPERATE & 0,99 \\
\hline MARA & 0,44 & NUXIS & 0,89 & SIDDI & 0,99 & FURTEI & 0,99 \\
\hline ESTERZILI & 0,44 & SERRI & 0,90 & DECIMOPUTZU & 0,99 & PERDAXIUS & 0,99 \\
\hline SINNAI & 0,47 & SANT'ANTIOCO & 0,90 & SARROCH & 0,99 & SIMALA & 0,99 \\
\hline GHILARZA & 0,48 & GESTURI & 0,90 & GONNOSCODINA & 0,99 & VILLAMAR & 0,99 \\
\hline SELEGAS & 0,51 & DONORI & 0,91 & DOMUSNOVAS & 0,99 & ASSEMINI & 0,99 \\
\hline GONNOSTRAMATZA & 0,52 & ATZARA & 0,91 & SANLURI & 0,99 & FORDONGIANUS & 1 \\
\hline SIAMAGGIORE & 0,53 & SENIS & 0,91 & SAMATZAI & 0,99 & & \\
\hline
\end{tabular}

\begin{tabular}{|c|c|c|c|c|c|c|c|}
\hline \multicolumn{2}{|l|}{ Cluster two } & \multicolumn{2}{|c|}{ Cluster three } & \multicolumn{4}{|c|}{ Cluster Four } \\
\hline Municipality & $m$ & Municipality & $m$ & Municipality & $m$ & Municipality & $m$ \\
\hline SEUI & 0,18 & TERTENIA & 0,20 & VILLAGRANDE STRISAILI & 0,19 & OZIERI & 0,30 \\
\hline ARZANA & 0,18 & OLLOLAI & 0,21 & ARITZO & 0,21 & POZZOMAGGIORE & 0,31 \\
\hline TALANA & 0,20 & OSINI & 0,22 & SANTU LUSSURGIU & 0,21 & BOLOTANA & 0,31 \\
\hline ALA DEI SARDI & 0,21 & BORUTTA & 0,22 & ARBUS & 0,21 & SINDIA & 0,31 \\
\hline ONANI & 0,21 & ROMANA & 0,23 & DESULO & 0,22 & SILANUS & 0,31 \\
\hline SCANO MONTIFERRO & 0,22 & GADONI & 0,23 & ALGHERO & 0,22 & SARULE & 0,32 \\
\hline TORRALBA & 0,23 & TISSI & 0,24 & SEMESTENE & 0,24 & NUORO & 0,32 \\
\hline SEDINI & 0,23 & TRIEI & 0,24 & OSCHIRI & 0,24 & $\begin{array}{l}\text { VILLANOVA } \\
\text { MONTELEONE }\end{array}$ & 0,32 \\
\hline OSIDDA & 0,24 & $\begin{array}{l}\text { SANTA MARIA } \\
\text { COGHINAS }\end{array}$ & 0,24 & LULA & 0,25 & FONNI & 0,33 \\
\hline
\end{tabular}


Table 1 (continued)

\begin{tabular}{|c|c|c|c|c|c|c|c|}
\hline \multicolumn{2}{|c|}{ Cluster two } & \multicolumn{2}{|c|}{ Cluster three } & \multicolumn{4}{|c|}{ Cluster Four } \\
\hline Municipality & $m$ & Municipality & $m$ & Municipality & $m$ & Municipality & $m$ \\
\hline VIDDALBA & 0,24 & FLUSSIO & 0,25 & STINTINO & 0,26 & SUNI & 0,33 \\
\hline AIDOMAGGIORE & 0,24 & PORTO TORRES & 0,25 & SASSARI & 0,26 & ORANI & 0,35 \\
\hline BULZI & 0,26 & CHEREMULE & 0,25 & BITTI & 0,26 & BONO & 0,36 \\
\hline BADESI & 0,26 & TINNURA & 0,25 & MAMOIADA & 0,26 & MACOMER & 0,36 \\
\hline LOCULI & 0,28 & SAGAMA & 0,26 & BOTTIDDA & 0,26 & CUGLIERI & 0,37 \\
\hline DUALCHI & 0,29 & CASTELSARDO & 0,26 & ORGOSOLO & 0,26 & BONORVA & 0,38 \\
\hline \multirow[t]{11}{*}{ BORORE } & 1 & SENNARIOLO & 0,27 & BERCHIDDA & 0,26 & BULTEI & 0,38 \\
\hline & & ABBASANTA & 0,28 & BESSUDE & 0,27 & OLZAI & 0,39 \\
\hline & & MAGOMADAS & 0,28 & TERGU & 0,27 & BORTIGALI & 0,39 \\
\hline & & TRESNURAGHES & 0,29 & BIRORI & 0,27 & ITTIREDDU & 0,41 \\
\hline & & NORBELLO & 1 & DORGALI & 0,28 & ORUNE & 0,41 \\
\hline & & & & SEDILO & 0,28 & MORES & 0,43 \\
\hline & & & & COSSOINE & 0,28 & BOSA & 0,45 \\
\hline & & & & PADRIA & 0,29 & ONIFERI & 0,45 \\
\hline & & & & THIESI & 0,29 & OROTELLI & 0,53 \\
\hline & & & & BENETUTTI & 0,29 & OLIENA & 0,57 \\
\hline & & & & GIAVE & 0,30 & OTTANA & 1 \\
\hline \multicolumn{5}{|c|}{ Cluster Five } & \multicolumn{3}{|c|}{ Cluster six } \\
\hline Municipality & $m$ & Munic & & $m$ & & lity & $m$ \\
\hline SEULO & 0,21 & ERL & & 0,40 & NUGH & NICOLO & 0,19 \\
\hline BAUNEI & 0,23 & POS & & 0,42 & & & 0,19 \\
\hline CHIARAMONTI & 0,23 & TRINITA D'AGU & GNOLA & 0,42 & & & 0,19 \\
\hline BONNANARO & 0,24 & BORTIC & & 0,43 & & & 0,21 \\
\hline NULE & 0,24 & TOI & & 0,46 & & & 0,22 \\
\hline URI & 0,24 & SAN TE & & 0,47 & & & 0,22 \\
\hline SORSO & 0,24 & PAI & & 0,50 & & ARI & 0,22 \\
\hline ARMUNGIA & 0,25 & GOLFO & & 0,66 & & & 0,22 \\
\hline GALTELLI & 0,25 & MO & & 0,71 & & TO & 0,23 \\
\hline IRGOLI & 0,26 & TEMPIO $\mathrm{F}$ & & 0,76 & & MARIA & 0,24 \\
\hline LAERRU & 0,26 & AGLI & & 0,86 & & & 0,29 \\
\hline LOTZORAI & 0,27 & $\mathrm{OL}$ & & 0,89 & & & 0,31 \\
\hline ILBONO & 0,27 & CALAN & & 0,93 & & & 0,32 \\
\hline ELINI & 0,28 & PAI & & 0,95 & & & 0,34 \\
\hline BANARI & 0,28 & LUI & & 0,97 & & & 0,36 \\
\hline AGGIUS & 0,28 & SANT'ANTONI & LURA & 0,97 & & & 0,43 \\
\hline BIDONI & 0,28 & SANTA TERE & URA & 0,97 & & & 0,48 \\
\hline SINISCOLA & 0,29 & $\mathrm{TE}$ & & 0,97 & & ANOS & 0,52 \\
\hline ONIFAI & 0,29 & ARZAC & & 0,98 & & & 1 \\
\hline OLMEDO & 0,30 & LUOGO & & 0,98 & & & \\
\hline OROSEI & 0,31 & LOIRI PORTC & OLO & 1 & & & \\
\hline LODE & 0,32 & & & & & & \\
\hline MARTIS & 0,34 & & & & & & \\
\hline TULA & 0,34 & & & & & & \\
\hline PERFUGAS & 0,35 & & & & & & \\
\hline BUDONI & 0,38 & & & & & & \\
\hline
\end{tabular}

Cluster four is centered in Ottana, which is surrounded by a group of municipalities primarily involved in advancing the dairy industry, which is certainly the driving force of this group. In the past decades, Ottana played a role in the industrial sector (King, 1975). Due to the industrial production crises, it switched slowly from industry to husbandry. With reference to the other municipalities of the cluster, it is well known that in Sardinia the economy of Thiesi is sustained by its excellence in the dairy field, and the provision of high quality milk. This has allowed the municipality to gain and ensure itself a stable place in the global market. This has been guaranteed through the prominence of organic farming that is characterized by organic pasturing for cattle. Dairy combined with husbandry is an essential condition for its innovative and well compensated agricultural production. Analogous justification could be made for the inclusion of Macomer, Ozieri and Sarule in the fourth cluster, where the agri-environmental area has increased along the years (Manca, 2015). Moreover, they show similar topographic and geomorphological characteristics and an advanced form of agriculture management, dominated by farmers that rent, even if the other forms of management, such as outright ownership are well represented. Renting represents a flexible contract that allows farmers the ability to adapt their production practices to market requirements.

Cluster five, surrounding Loiri San Paolo, has interesting geographic neighbors. Even if the percentage of organic area extension is not significant, it is strongly supported by owner management. Although the agricultural and pastoral transformation does not appear to be significant, it is worth noting that organic agriculture supports the tourist economy. This cluster includes the municipalities of a well-developed tourist area known as Costa Smeralda which sustains a tourist industry during the summer season that offers an alternative to luxury services (Manca and De Montis, 1999). The geography of the region includes scenic attractions including rivers that flow down to the coast and is characterized by agricultural and tourist developments such as agritourist farms.

Cluster six is centered around its medoid, the municipality of Osilo. It has homogeneous characteristics based on geographical features and demographic structures. It is located 600 meters above sea level; moreover, its demographic status indicates a stagnant or declining population. This is a consequence of an unsatisfactory SMD, affecting 


\section{Six Clusters Deformed}

\section{Cluster 1}

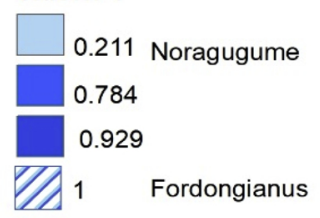

Cluster 2

$\square_{1}^{0.182 \text { Seui }}$

\section{Cluster 3}

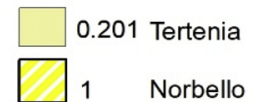

\section{Cluster 4}

0.185 Villagrande Strisaili D Ottana

\section{Cluster 5}

$\square .214$ Seulo
$Z_{\text {Cluster } 6}$ Loiri Porto San Paolo

Cluster 6

0.188 Nughedu San Nicolò

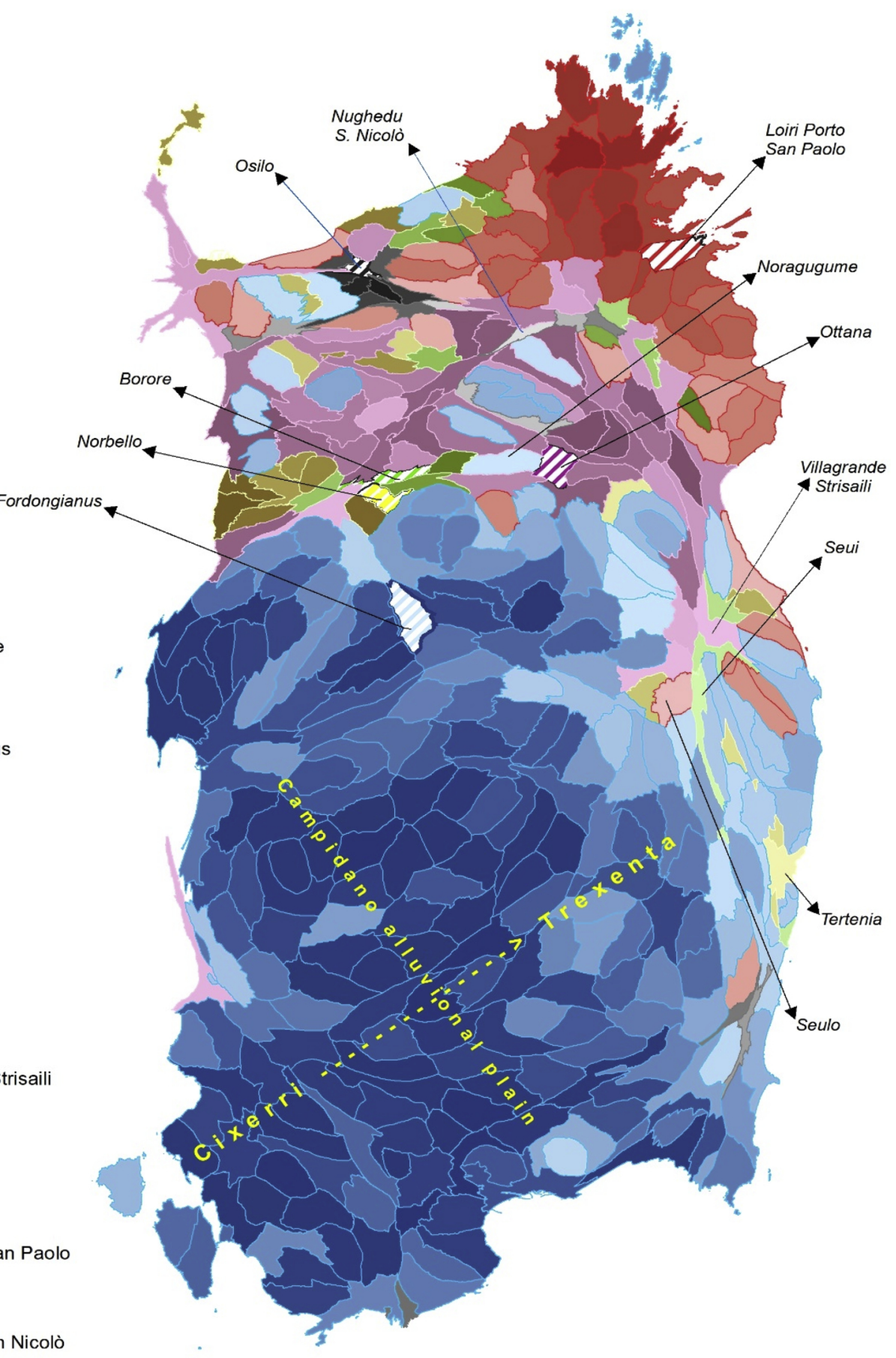

Fig. 2. The spatial exaggeration of the clusters displayed as a cartogram.

the whole county. Essentially Osilo is facing a demographic decline. The adjacent municipalities share almost the same demographic structure index as Osilo and also face demographic decline and the same challenges in agricultural development. It is an intriguing hypothesis to link this cluster to the agri-environmental measure beyond the traditional agriculture development and suggest that it is not useful to make assumptions based solely on the similar demographic structures of the municipalities. Cluster six is principally characterized by local organic grazing which is well distributed throughout the cluster area. Traditional farm produce is commonly sold in the local markets. The agri-environmental measure is extended not only over the owner property but also toward a high rate of land rent. Rent management is a flexible tool used to increase the extension of the area under the measure benefit and it is not a constraint. Indeed, it should last until the end of funding season, essentially several years, allowing the farmer to leave the land when the funding is over. The demographic structure does not affect the analysis because the municipalities are so similar in their demographic profiles. It is expected that at the end of the funding 
season, the agri-environmental area will shrink because production will still be based on local markets and demographic growth will remain stagnant throughout the cluster. Although funding will last up to 2020, it is mandatory to prevent the abandonment of the land, thus it will be necessary to increase the amount of funding for farmers that are inclined to develop an integrated chain of production and thus are able to grow the economy.

\section{Conclusions}

The suggested SFPAM approach answers graphically and statistically where the EU funds allocate resources in most needed area. The funds spread over areas, which are mostly under a low level of demographic health and differentiate themselves between development and stagnation. The funds reached the stagnation areas, either economic or social-demographical, providing fuel to let survive the agricultural production and related activities, imposing new paradigms to boost the organic production. The method has produced an effective way to communicate and inform how the spatial approach that considers geography as a factor in measuring the success of the AEM can be combined with the economic and agriculture structures of the municipalities within the clustering method. SFPAM merges the fuzzy clustering approach, the PAM strategy and the use of spatial information to pinpoint "hotspots" in order to determine an appropriate distribution of funds. The fuzzy approach for regional development in the AEM measure has been widely applied by several authors, bringing attention to how it can discriminate organic farming and sustainable agriculture over an area and provide an understanding, at a regional scale, of which factors have influenced the success of the AEM measure. In addition to the fuzzy approach, PAM identifies the municipality, as an observed object and not as a fictitious or calculated location such as a centroid as happens in the c-means clustering approach. The PAM approach is also more robust than c-means clustering with respect to the influence of outliers. Moreover, the method incorporates spatial information in this regional dataset, namely the spatial dependence and spatial heterogeneity exhibited by the variables. It does this by considering the idea of adjacency among the municipalities. The method discloses how the municipal groupings are affected by their geographical relationships. It accomplishes this by locating together in the same group those municipalities that have almost the same membership values.

The superiority of the SFPAM approach over the traditional approach is determined by its ability to locate group members together around their medoids. This resulted in six clusters of municipalities that are characterized by their similar economic development, agriculture structures and locations. This peculiarity, with respect to the fuzzy cmeans clustering, in identifying the "observed object", the municipality, allows us to address political and economic actions that characterize developments not only in the agri-environmental sector, but also in other sectors. Instead of coping with the complexity of uncertain, inadequately defined groupings and clusters, the SFPAM identified medoid municipalities that have a specific geographical location that permits policy makers to focus their financial strategies and interventions. Certainly, the suggested methodological approach is consistent with the regional development aims which would guide decisions related either to pursuing political actions toward the AEM initiatives of organic farming and/or agri-environmental agriculture or would financially supporting the various economic activities identified in this research. Apparently, at glance, the AEM have had a tremendous impact in the area of traditional agriculture, represented by the cluster one, timidly placed in oriental coast, strongly reinforced its presence in the northern area. The pattern is politically sustainable and equal, because majority of the municipalities have been reached by the agrienvironmental funds. Moreover, the results also provide important policy implications to determine where and when financial efforts should be renewed, where to negotiate sustainable development strategies, and how to expand spatially the benefits of financial funding to other agricultural measures, such as technological innovation in agriculture, reforestation programs, marketing strategies, climate change mitigation, and rural development.

\section{References}

Bateman, I.J., Harwood, A.R., Mace, G.M., Watson, R.T., Abson, D.J., Andrews, B., 2013. Bringing ecosystem services into economic decision-making: land use in the United Kingdom. Science 341 (6141), 45-50. https://doi.org/10.1126/science.1234379.

Bottazzi, G., Puggioni, G., 2012. Lo spopolamento in Sardegna come tendenza di lungo periodo. In: Breschi, M. (Ed.), Dinamiche demografiche in Sardegna tra passato e futuro. Forum, Udine, pp. 73-96.

Burton, R.J.F., Schwarz, G., 2013. Result-oriented agri-environmental schemes in Europe and their potential for promoting behavioral change. Land Use Policy 30, 628-641. https://doi.org/10.1016/j.landusepol.2012.05.002.

Coppi, R., D'Urso, P., Giordani, P., 2010. A fuzzy clustering model for multivariate spatial time series. J. Classif. 27, 54-88. https://doi.org/10.1007/s00357-010-9043-y.

Diti, I., Tassinari, P., Torregiani, D., 2015. The agri-environmental footprint: a method for the identification and classification of peri-urban areas. J. Environ. Manage. 165, 250-262.

D’Urso, P., 2015. Fuzzy clustering. In: Hennig, C., Meila, M., Murtagh, F., Rocci, R. (Eds.), Handbook of Cluster Analysis, pp. 545-574.

D’Urso, P., De Giovanni, L., Massari, R., 2015. Trimmed fuzzy clustering for intervalvalued data. Adv. Data Anal. Classif. 9 (1), 21-40. https://doi.org/10.1007/s11634. 014-0169-3.

Everitt, B.S., Landau, S., Leese, M., 2001. Cluster Analysis, 4th ed. Arnold Press, London.

Franco, S., Senni, S., 2003. La modulazione territoriale delle politiche di sviluppo rurale: una proposta metodologica. In: Arzeni, A., Esposti, R., Sotte, F. (Eds.), Politiche di Sviluppo Rurale tra Programmazione e Valutazione. Franco Angeli, Milan, pp. 139-150.

Galler, C., von Haaren, C., Albert, C., 2015. Optimizing environmental measures for landscape multifunctionality: effectiveness, efficiency and recommendations for agrienvironmental programs. J. Environ. Manage. 151, 243-257. https://doi.org/10. 1016/j.jenvman.2014.12.011.

Gastner, M.T., Newmann, M.E.J., 2004. Diffusion-based method for producing densityequalizing maps. PNAS 101 (20). https://doi.org/10.1073/pnas.0400280101.

Gordon, A.D., 1996. A survey of constrained classification. Comput. Stat. Data Anal. 21, 17-29. https://doi.org/10.1016/0167-9473(95)00005-4.

Heiser, W.J., Groenen, P.J.F., 1997. Cluster differences scaling with a within-clusters loss component and a fuzzy successive approximation strategy to avoid local minima. Psychometrika 62, 63-83. https://doi.org/10.1007/BF02294781.

Idda, L., Furesi, R., Pulina, P., 2010. Economia dell'allevamento ovino da latte. Produzione, trasformazione, mercato. Franco Angeli, Milan.

Kamdar, T., Joshi, A., 2000. On creating Adaptive Web Servers Using Weblog Mining (Technical Report TR-CS-00-05). Department of Computer Science and Electrical Engineering, University of Maryland, Baltimore County.

King, R., 1975. Ottana: an attempt to bring industry to Sardinia's shepherd-bandits. Geography 60 (3), 218-222. http://www.jstor.org/stable/40568427.

Ligda, C., Tchakerian, E., Zotos, E., Georgoudis, A., 2011. Tradition and innovation in the Mediterranean pastoralism: recognition of its multiple roles for sustainable development of rural areas. In: Bouche, R., Derkimba, A., Casabianca, F. (Eds.), Trends for Innovation in the Mediterranean Animal Production. Wageningen Academic Publishers. https://doi.org/10.3920/978-90-8686-726-4_42. ISBN: 978-90-8686726-4.

Lobianco, A., Esposti, R., 2010. The Regional Multi-Agent Simulator (RegMAS): an opensource spatially explicit model to assess the impact of agricultural policies. Comput. Electron. Agric. 72 (1), 14-26. https://doi.org/10.1016/j.compag.2010.02.006.

Manca, G., De Montis, A., 1999. Economic forecast and fuzzy spatial analysis: integrated tools for assessing the development tendency of an Italian region. ERSA Conference Papers, European Regional Science Association, Dublin, Ireland.

Manca, G., Attaway, D., Waters, N., 2014. Implications of the European agri-environmental program in the region of Sardinia, Italy: discovering the outcomes using geographical weighted regression and fuzzy analysis. Appl. Geogr. 50, 24-30. https://doi.org/10.1016/j.apgeog.2014.01.014.

Manca, G., 2015. Modeling European agri-environmental measure of spatial impact in the region of Sardinia, Italy, through fuzzy clustering means. Econ. Agro-Alimentare 1, 13-27. https://doi.org/10.3280/ECAG2015-001002.

Matthews, K.B., Bucham, K., Miller, D.G., Towers, W., 2013. Reforming the CAP-with area-based payments, who wins and who loses? Land Use Policy 31, 209-222. https://doi.org/10.1016/j.landusepol.2012.06.013.

McBratney, A.B., Moore, A.W., 1985. Application of fuzzy sets to climatic classification. Agric. Forest Meteorol. 35, 165-185. https://doi.org/10.1016/0168-1923(85) 90082-6.

Murtagh, F., 1985. A survey of algorithms for contiguity-constrained clustering and related problems. Comput. J. 28, 82-88. https://doi.org/10.1093/comjnl/28.1.82.

Palmisano, G.O., Govindan, K., Loisi, R.V., Dal Sasso, P., Roma, R., 2016a. Greenways for rural sustainable development: an integration between geographic information systems and group analytic hierarchy process. Land Use Policy 50, 429-440. https://doi. org/10.1016/j.landusepol.2015.10.016.

Palmisano, G.O., Govindan, K., Boggia, A., Loisi, R.V., De Boni, A., Roma, R., 2016b. Local action groups and rural sustainable development. A spatial multiple criteria approach for efficient territorial planning. Land Use Policy 59, 12-26. https://doi.org/10. 1016/j.landusepol.2016.08.002.

Pham, D.L., 2001. Spatial models for fuzzy clustering. Comput. Vis. Image Underst. 84, 
285-297. https://doi.org/10.1006/cviu.2001.0951.

Qiuzhen, C., Sipilainen, T., Sumelius, J., 2012. Assessment of Agri-environmental Public Goods Proving Using Fuzzy Synthetic Evaluation (Discussion Papers n. 61). Department of Economics and Management, Helsinkihttps://doi.org/10.3390/ su6063171.

Riley, M., 2016. Still being the 'good farmer': (non) retirement and the preservation of farming identities in older age. Sociol. Ruralis 56, 96-115. https://doi.org/10.1111/ soru. 12063 .

Tsekouras, E.G., 2007. Implementing hierarchical fuzzy clustering in fuzzy modeling using the weighted fuzzy c-means. In: Valente de Oliveira, J., Pedrycz, W. (Eds.), Advanced in Fuzzy Clustering and Its Applications. John Wiley and Sons, New York, pp. 246-263. https://doi.org/10.1002/9780470061190.ch12.

Tsekouras, E.G., 2005. On the use of the weighted fuzzy c-means in fuzzy modeling. Adv. Eng. Softw. 36, 287-300. https://doi.org/10.1016/j.advengsoft.2004.12.001.

Vargas-Cetina, G., 2000. From handicraft to Monocrop: the production of Pecorino cheese in highland Sardinia. In: Haugerud, A., Stone, M.P., Little, P.D., Society for Economic Anthropology (U.S.) (Eds.), Commodities and Globalization: Anthropological
Perspectives. Rowman \& Littlefield, Lanham, MD, pp. 219-224.

Waters, N.M., 2017. Tobler's first law of geography. In: Richardson, D., Castree, N., Goodchild, M.F., Kobayashi, A., Liu, W., Marston, R. (Eds.), International

Encyclopedia of Geography: People, the Earth, Environment, and Technology. Wiley, New York.

Weber Reuschel, A.K., Piatti, B., Hurni, L., 2014. Data-driven expansion of dense regions-a cartographic approach in literary geography. Cartogr. J. 51 (2), 123-140. https://doi.org/10.1179/1743277414Y.0000000077.

Wedel, M., Kamakura, W.A., 1998. Market Segmentation: Conceptual and Methodological Foundations. Kluwer Academic, Boston.

Xia, Y., Feng, D., Wang, T., Zhao, R., Zhang, Y., 2007. Image segmentation by clustering of spatial patterns. Pattern Recognit. Lett. 28, 1548-1555. https://doi.org/10.1016/j. patrec. 2007.03.012.

Yang, A.L., Rounsevell, M.D.A., Wilson, R.W., Haggett, C., 2014. Spatial analysis of agrienvironmental policy uptake and expenditure in Scotland. J. Environ. Manage. 133, 104-115. https://doi.org/10.1016/j.jenvman.2013.11.038. 